\title{
Justiça restaurativa à luz dos direitos humanos: fundamentos a partir de Paulo Freire
}

Restorative justice in the light of human rights: fundamentals from Paulo Freire

\author{
Valdênia Brito Monteiro \\ valdenia.brito@unicap.br \\ Doutoranda pela Universidade Católica de \\ Pernambuco-UNICAP, mestra em Direito \\ Público pela Universidade Federal de \\ Pernambuco - UFPE, professora e \\ coordenadora do Curso de Especialização \\ em Direitos Humanos (Unicap).
}

\begin{abstract}
Resumo
O artigo é uma discussão sobre justiça restaurativa à luz dos direitos humanos, a partir das contribuições teóricas de Paulo Freire sobre a concepção de diálogo, autonomia, conscientização e respeito. O trabalho é de cunho bibliográfico. Por fim, o artigo reflete caminhos para uma concepção de justiça restaurativa com base nos ideais freirianos de educação libertadora, tendo como fundamento o diálogo.

Palavras-chave: educação libertadora; diálogo; cultura de paz.
\end{abstract}

\section{Abstract}

The article is a discussion on restorative justice in the light of human rights, based on Paulo Freire's theoretical contributions on the concept of dialogue, autonomy, wariness and respect. The research is bibliographical. Finally, the article reflects paths towards to a conception of restorative justice based on Freire's ideals of liberating education, based on dialogue.

Keywords: liberaring education; dialogue; culture of peace 
MONTEIRO, Valdênia Brito. Justiça restaurativa à luz dos direitos humanos: fundamentos a partir de Paulo

\section{Introdução}

A partir do século XX, o caráter universal dos direitos humanos, com a Declaração de 1948, torna-se marco do direito internacional de proteção dos direitos fundamentais a serem respeitados pelos Estados. O reconhecimento dos direitos humanos pode ser visto entre as grandes invenções da humanidade se comparado aos avanços em outras áreas do conhecimento. No entanto, Bobbio diz que "o problema maior não é justificar esses direitos, mas protegê-los" (1992, p.25).

O princípio da dignidade humana consagrou-se como um grande paradigma do fundamento dos direitos humanos, baseado na ética em prol da pessoa humana e da atuação dos sujeitos de direito capazes de promover ações que alterassem situações de exclusão. Santos (2016) afirma ser incontestável a concepção dos direitos humanos como "linguagem de dignidade humana", no entanto questiona o seu caráter hegemônico. "A grande maioria da população mundial não é sujeito de direitos. É objeto de discursos de direitos humanos" (Santos, 2013, p.42). O autor vai chamar de "realidade perturbadora". Propõe uma concepção contrahegemônica que tem como ponto de partida a "hermenêutica da suspeita em relação aos direitos humanos, isto é, em relação às concepções diretamente vinculadas à sua matriz liberal e ocidental" (Santos, 2013, p.43).

Diante dos grandes percalços e contradições da concepção de direitos fundamentais, há uma série de contribuições de autores de matriz crítica latino-americana que vêm refletindo sobre a construção de uma cultura de paz, com base na educação libertadora. Paulo Freire se destaca como referencial da proposta de educação ancorada na liberdade, no respeito pelos saberes do educando, no diálogo, na autonomia e transformação dos seres humanos.

O artigo reflete sobre a justiça restaurativa à luz dos direitos humanos, trazendo a reflexão sobre a cultura de paz como um caminho possível. A pesquisa bibliográfica está embasada principalmente nas contribuições de Paulo Freire sob educação e de outros autores que escrevem sobre métodos alternativos de resolução de conflito. Por fim, o artigo traz caminhos para uma concepção de justiça restaurativa com base na educação libertadora, tendo como fundamento o diálogo. 
MONTEIRO, Valdênia Brito. Justiça restaurativa à luz dos direitos humanos: fundamentos a partir de Paulo

\section{Direitos humanos e cultura de paz}

A Declaração Universal de Direitos Humanos ${ }^{1}$ foi criada com o intuito da paz. No seu preâmbulo, estabelece que a implementação dos direitos humanos fique vinculada a um compromisso de uma intervenção educativa, buscando, enquanto ideal, atingir todos os povos e todas as nações. Nesse sentido, coloca a educação como processo e em construção com todas as pessoas.

Paulo Freire, em Pedagogia do Oprimido, faz uma denúncia da desumanização vivida pelos seres humanos pelos processos de opressão a partir de uma ação autoritária ${ }^{2}$ que viola os direitos fundamentais, por sua vez, a dignidade humana.

Os oprimidos são os que não têm voz, são coisificados, são os impedidos de pensar e ter consciência. Dentre tantas denominações usadas por Freire, ele expressa "demitido da vida" (Freire, 2005, p.31). “É precisamente porque reduzidos a quase 'coisas', na relação de opressão em que estão, que se encontram destruídos. (...) A opressão, que é um controle esmagador, é necrófila" (Freire, 2005, p.60-74). Em síntese, a opressão nutre a morte. "Nutre-se do amor à morte e não do amor à vida" (Freire, 2008, p.74). O autor, em vários momentos, afirma que a opressão é reflexo de uma estrutura de dominação que não abre espaço para a construção de uma cidadania libertária, mas para a cultura do silêncio.

Neste sentido, Mbembe (2018) apresenta uma discussão sobre a micropolítica, como ferramenta teórica para compreender a ação política contemporânea, o poder soberano com "o poder e a capacidade de ditar quem pode viver e quem deve morrer" $(2018, \text { p.5 })^{3}$. O autor apresenta reflexões teóricas a partir da influência de Michel Foucault, desde a ideia de "biopoder", desenvolvida pelo filósofo francês.

Para Mbembe (2018), os efeitos da escravidão e do colonialismo continuam, nos países periféricos, oprimindo a população. Os processos de violência, desigualdade, exploração de recursos naturais marcam os territórios sob o signo da colonialidade como formas coloniais de dominação, mesmo após o fim das administrações coloniais ${ }^{4}$.

\footnotetext{
1 Proclamada pela Assembleia Geral das Nações Unidas em Paris, em 10 de dezembro de 1948, estabelece, pela primeira vez, a proteção universal dos direitos humanos.

${ }^{2}$ Em Pedagogia do Oprimido, Freire apresenta uma grande preocupação com a situação da América Latina pela expansão de regimes ditatoriais iniciada na década de 1960. Faz uma discussão sobre a experiência antidemocrática que traz menos conhecimento crítico e participação.

${ }^{3}$ Embora Mbembe se concentre mais na colonização da África e na questão Palestina, é possível, dentro do debate decolonial, encontrar apontamentos que nos auxiliem nas reflexões sobre a opressão. ${ }^{4}$ Quijano (2009) é o autor que traz, originalmente, a reflexão sobre o significado de colonialidade.
}

DIGNIDADE RE-VISTA | ISSN2525-698X| 2021 | V. VII | N. 12 | Educação Prática Libertadora - heranças dos 100 anos de Paulo Freire e Dom Paulo Arns. Pastoral Universitária Anchieta PUC-RIO. 
O pensamento da pedagogia crítica freiriana questiona as dinâmicas da colonialidade, evidenciadas na opressão: “(...) não haveria oprimidos se não houvesse uma relação de violência que os conforma como violentados, numa situação objetiva de opressão" (Freire, 2005, p.45). Freire mostra que há contradições nos oprimidos. São "hospedeiros' do opressor" (2005, p.32), padecem uma "dualidade": "São eles [oprimidos] e ao mesmo tempo são o outro introjetado neles, como consciência opressora" - "este é o trágico dilema dos oprimidos" (Freire, 2005, p.36). O autor fala do medo da liberdade, que “(...) tanto pode conduzi-los a pretender ser opressores também, quanto pode mantê-los atados ao status de oprimidos" (2005, p.34).

A humanização é uma vocação histórica, no sentido de uma tendência natural do humano. A pedagogia freiriana traz caminhos para uma cultura de paz a partir de uma perspectiva crítica. Como expressa Ana Maria Freire:

(...) para Paulo a Paz não é um dado, um fato intrinsecamente humano comum a todos os povos, de quaisquer culturas. Precisamos, desde a mais tenra idade formar as crianças na "Cultura da Paz", que necessita desvelar e não esconder, com criticidade ética, as práticas sociais injustas, incentivando a colaboração, a tolerância com o diferente, o espírito de justiça e da solidariedade. (Freire, 2006, p.391)

A obra freiriana traz vários elementos catalizadores e necessários para uma prática educativa. $\mathrm{O}$ autor diz que a única forma de romper com a desumanização é a educação consciente, como processo de libertação. "O primeiro objetivo de toda a educação: antes de tudo, provocar uma atitude crítica, de reflexão, que comprometa a ação" (2007, p.46). Argumenta Freire:

(...) não pode existir uma prática educativa neutra, descomprometida, apolítica. A diretividade da prática educativa que a faz transbordar sempre de si mesma e perseguir um certo fim, um sonho, uma utopia, não permite sua neutralidade. (2007, p.37)

Pedagogia da Esperança é uma obra de Freire (1996) que reforça a crença no ser humano oprimido a lutar contra a opressão em favor da vida, para que o homem possa achar-se merecedor de consideração.

Enquanto andávamos pelas ruas daquele mundo maltratado e ofendido eu ia me lembrando de experiências de minha juventude em outras favelas de Olinda ou do Recife, dos meus diálogos com favelados e favelados de alma 
rasgada. Tropeçando na dor humana, nós nos perguntávamos em torno de um sem número de problemas. Que fazer, enquanto educadores, trabalhando num contexto assim? Há mesmo o que fazer? Como fazer o que fazer? (Freire, 1996, p.44)

$\mathrm{O}$ autor discute a possibilidade do aprimoramento de uma sensibilidade humana que seja capaz de compreender o sofrimento e se colocar no lugar do outro. A essência da sua pedagogia é a libertação, que tem como caminho a práxis. Esta é reflexão e ação dos homens sobre o mundo para transformá-lo. "Não é no silêncio que os homens se fazem, mas na palavra, no trabalho, na ação reflexão" (Freire, 2005, p.78). Freire acredita na libertação do homem aprisionado, mas tem clara a necessidade da superação opressor-oprimido.

Nos seus diálogos sobre a pedagogia libertadora, compreende a dor do outro, que nutre um sentimento de compaixão por entender a complexidade das amarras da opressão. Por isso, pode-se dizer que o autor cria uma pedagogia voltada para os direitos humanos a partir de uma prática que reflete e compartilha histórias tristes e sentimentais que comovem todos e todas. Em outros termos, estímulo a uma troca, ao experienciar a realidade do outro que sofre. Teoria e prática estariam interligadas a partir de vivências intersubjetivas. Os violadores de direitos humanos têm uma compreensão do significado de direitos fundamentais, mas o problema é que eles consideram suas vítimas enquanto não humanas. A proposta de Freire é a educação como processo de humanização

(...) se falamos da humanização, do ser mais do homem - objetivo básico de sua busca permanente - reconhecemos o seu contrário: a desumanização, o ser menos. Ambas, humanização e desumanização são possibilidades históricas do homem como um ser incompleto e consciente de sua incompleticidade. Tão somente a primeira, contudo, constitui a sua verdadeira vocação. A segunda, pelo contrário, é a distorção da vocação. (Freire, 2005, p.127)

A proposta freiriana é de construção de um pensar engajado que significa um pensar crítico da realidade. É de um olhar da realidade latino-americana, onde ainda pairam lógicas eurocêntricas ${ }^{5}$. Em outros termos, o autor tinha claro que só com uma educação como prática libertadora é possível lutar contra um regime opressor. Uma educação para a solidariedade faz

\footnotetext{
${ }^{5}$ A lógica eurocêntrica se caracteriza como um sistema ideológico em que a cultura europeia se apresenta como o centro de poder no mundo, principalmente com a colonização. Sobre o assunto: QUIJANO, Anibal. A colonialidade do poder, eurocentrismo e América Latina. In: Lander, E. (Org). A colonialidade do saber: eurocentrismo e ciências sociais. Buenos Aires: Clacso, 2005.
} 
MONTEIRO, Valdênia Brito. Justiça restaurativa à luz dos direitos humanos: fundamentos a partir de Paulo

a construção de um mundo novo possível; uma cultura de paz faz com que o coletivo possa desenvolver o respeito ao diferente, como condição moral básica de respeito humano.

Em 1998, Paulo Freire ganha o prêmio da Organização das Nações Unidas para Educação, Ciência e Cultura - Unesco/ONU de Educador para a Paz. No seu discurso de agradecimento, ele expressa o significado de educar para a paz:

De anônimas gentes, sofridas gentes, exploradas gentes aprendi, sobretudo, que a Paz é fundamental, indispensável, mas que a Paz implica lutar por ela. A Paz se cria, se constrói na e pela superação de realidades sociais perversas. A Paz se cria, se constrói na construção incessante da justiça social. Por isso, não creio em nenhum esforço chamado de educação para a Paz que, em lugar de desvelar o mundo das injustiças, o torna opaco e tenda a miopizar as suas vítimas. (Freire, 2006, p.388)

Em 1999, a ONU anunciou a Declaração e Programa de Ação sobre uma Cultura de Paz, que expressa a sedimentação realizada por Paulo Freire sobre a cultura de paz:

\footnotetext{
No respeito e fomento à igualdade de direitos e oportunidades de mulheres e homens; no respeito e fomento ao direito de todas as pessoas à liberdade de expressão, opinião e informação; (...) na adesão aos princípios de liberdade, justiça, democracia, tolerância, solidariedade, cooperação, pluralismo, diversidade cultural, diálogo e entendimento em todos os níveis da sociedade e entre as nações; e animados por uma atmosfera nacional e internacional que favoreça a paz. (ONU, 2004)
}

A cultura de paz freiriana coloca mulheres e homens como protagonistas de suas próprias histórias. Mas é uma paz que se constrói no diálogo. Por isso, a Justiça restaurativa, para alguns chamada mediação de conflitos, a partir dos fundamentos de Paulo Freire, é um meio alternativo para exercitar a cultura de paz.

\section{Justiça restaurativa: um caminho possível}

A justiça restaurativa como um dos meios alternativos de acesso à justiça extrajudicial é um movimento que se iniciou nas décadas de 1970 e 1980, frente às críticas ao sistema penal moderno (retributivo-punitivo). Tem como referências as tradições pacificadoras na Austrália e Nova Zelândia, com o intuito de, a partir do diálogo e valorização da autonomia, buscar a reparação do dano, não ficando restrita ao processo judicial. A Nova Zelândia, país pioneiro na implantação das práticas restaurativas, teve como inspiração os aoris. Percebeu que 
MONTEIRO, Valdênia Brito. Justiça restaurativa à luz dos direitos humanos: fundamentos a partir de Paulo

a justiça tradicional não dava conta de entender, por exemplo, o povo nativo. Nas comunidades ancestrais, o protagonismo se dava de forma comunitária. A resolução de conflito era a partir de práticas grupais, sustentadas pelo sentimento de pertença social.

Os meios alternativos de justiça na perspectiva dos direitos humanos, de uma cultura de paz freiriana, diferenciam-se por refletir sobre a importância do protagonismo cidadão como capaz de exigir e reinventar direitos e construir compromissos entre os indivíduos e grupos, como condição da cidadania ativa.

A ideia de justiça é de difícil conceituação, por isso que qualquer entendimento é provisório. Uma aproximação da noção de justiça envolve uma visão de mundo que vai desde a construção de cultura de paz, garantias e efetivação de direitos de liberdade, igualdade, solidariedade, até o direito à memória e à verdade. Ruiz expõe que a dimensão ética da justiça lhe confere potencialidade utópica para almejar uma vida mais digna possível para todos os seres humanos (2009, p.11).

É necessário entender a Justiça como um ideal utópico, como algo que sempre se está buscando. Para Paulo Freire, transgredir a utopia ${ }^{6}$ era o "inédito viável", como algo que se concretiza na luta diária. "Falo da utopia, pelo contrário, como necessidade fundamental do ser humano. Faz parte de sua natureza, histórica e socialmente constituindo-se, que homens e mulheres não prescindam, em condições normais, do sonho e da utopia” (Freire, 2001b, p.85). A justiça vinculada à alteridade humana e a um potencial ético deve ser vista como uma possibilidade constante de se restituir um direito que foi negado. O princípio ético freiriano é a partir da experiência da vida. Como bem frisou Dussel, uma "ética da vida", a partir dos oprimidos (2002, p.313).

Paulo Freire tinha preocupação com a justiça social, não só no Brasil, mas na América Latina. Acreditava na emancipação e autonomia dos seres humanos, capazes de romper as estruturas opressoras e as desigualdades sociais. A discussão sobre justiça também remete à ideia de conflito como elemento necessário e constitutivo da vida em comunidade e da realização da própria justiça. O conflito deve ser entendido como uma tensão positiva de visões, de ideias e opiniões. O conflito bem mediado pode contribuir para empoderamento de pessoas, melhoria das relações sociais e possibilidades de aprofundamento de desigualdades.

\footnotetext{
6 A utopia para Paulo Freire se caracterizava pela possibilidade da autonomia dos sujeitos e transformação social; na luta pela emancipação humana. Sua realização não se verifica facilmente sem obstáculos. "Implica, pelo contrário, avanços, recuos, marchas às vezes demoradas. Implica luta" (Freire, 2000, p. 54).
}

DIGNIDADE RE-VISTA | ISSN2525-698X| 2021 | V. VII | N. 12 | Educação Prática Libertadora - heranças dos 100 anos de Paulo Freire e Dom Paulo Arns. Pastoral Universitária Anchieta PUC-RIO. 
Para Lederach (1998), para compreender o conflito é necessário analisá-lo a partir de várias lentes, iniciando pela que parte da situação imediata e, em seguida, tomar outra "lente" para ver o passado dos problemas imediatos e as relações que dão contorno ao conflito. E a terceira "lente", que é utilizada para encontrar um marco de convergência, com o objetivo de discutir a busca de respostas ou soluções criativas. Pelizzoli (2012) diz que pensar os conflitos exige indagar como o meu "ser no mundo" tem-se exercido, o que me cabe diante da vida conflituosa, que envolve a mim e meus próximos; como tenho ferramentas para lidar com eles, como me preparei emocionalmente para lidar com eles, como posso ajudar outrem a lidar com eles? Há de se preguntar se sabemos ou queremos aprender a dialogar. Freire expõe que

O diálogo é este encontro dos homens, mediatizados pelo mundo para pronunciá-lo, não se esgotando, portanto, na relação eu-tu. Esta é a razão porque não é possível o diálogo entre os que querem a pronúncia do mundo e os que não querem; entre os que negam aos demais o direito de dizer a palavra e os que se acham negados deste direito. (2005, p.91)

Freire propõe o "diálogo do encontro que se expressa pelo reconhecimento e igualdade dos participantes do diálogo no uso da palavra, como ato de criação e recriação. Sem humildade não há diálogo" (2005, p.92). E coloca a seguinte pergunta: "Como posso dialogar, se alieno a ignorância, isto é, se a vejo sempre no outro, nunca em mim?” (Freire, 2005, p.93). Diz:

não existe diálogo sem esperança. Esta encontra-se na própria essência da imperfeição dos homens, levando-os a uma eterna busca. Uma tal busca não se faz no isolamento, mas na comunicação entre os homens o que é impraticável numa situação de agressão. (Freire, 2005, p.94-95)

A justiça restaurativa à luz dos direitos humanos tem como base o princípio da não violência, que, para Muller, "é uma atitude ética e espiritual do homem forte que reconhece a violação como negação da humanidade e que decide recusar submeter-se a seu domínio. A violência é um ato que transgride a complexidade entre as coisas e os homens" (2007, p.147). Esta proposta coaduna com o pensamento freiriano de uma Pedagogia da Esperança, quando expressava: "não há utopia verdadeira fora da tensão entre a denúncia e o anúncio de um futuro a ser criado, construído, política, estética e eticamente, por nós, mulheres e homens" (Freire, 1992, p.91).

Para Galtung, deve-se ter em mente as três preocupações da ação não violenta: 
a. ela deve ser orientada contra a relação entre o eu e o outro, não contra o outro;

b. deve ser conduzida de tal maneira que construa o amor e não o ódio, o comportamento pacífico em vez do violento;

c. o outro deve ser convidado a compartilhar sua experiência enriquecedora.

O fundamental que o conflito se transforme de modo construtivo. (2003, p.176)

O termo restaurar remete à concepção de restabelecer, refazer, recuperar, emendar o que foi destruído. A justiça restaurativa é uma resposta avançada à violência e ao crime, buscando oportunizar o diálogo entre o ofensor, a vítima e a comunidade envolvida, tentando romper com o ciclo da violência. Penido (2010) sintetiza que a justiça restaurativa recoloca a justiça como um valor construído de modo ativo na relação com o outro. Busca promover a harmonia social recuperando vítimas, infratores e comunidades. Transcende a dinâmica de culpa, vingança e etiquetamentos de pessoas. Nas palavras Zehr "a justiça restaurativa nos faz lembrar a importância dos relacionamentos, nos incita a considerar o impacto de nosso comportamento sobre o outro e as obrigações geradas pelas nossas ações" (2008, p.265).

A regulamentação da justiça restaurativa tem como marco inaugural a Resolução 2002/12 do Conselho Econômico e Cultural da Organização das Nações Unidas, que traz os princípios básicos para a utilização de Programas de Justiça Restaurativa em matéria criminal. Para isso, os valores que a regem são: empoderamento, participação, autonomia, respeito, responsabilização pelos danos causados e também na satisfação das necessidades evidenciadas a partir da situação de conflito. Todos esses valores refletidos por Paulo Freire como necessários para uma cultura de paz.

Mas, a justiça pode ser restabelecida quando violada? Zehr diz que "perdoar significa não mais permitir que a ofensa e o ofensor dominem. Sem essa experiência, a ferida (a violência) continuará dominando a consciência” (2008, p. 46). Reforça que o perdão é um ato de empoderamento e cura. Ele permite passar da condição de vítima à de sobrevivente.

A proposta restaurativa vai além da mera resolução processual dos conflitos, porque busca a restauração dos laços comunitários e dos laços entre vítima e infrator, como propulsora de paz e harmonia social. Para Penido (2005), a justiça restaurativa lança luz para a corresponsabilidade. Analisa as causas e as consequências do ato cometido. Olha para a responsabilidade tanto individual como coletiva.

Neste sentido, o diálogo é fundamental, pois através da palavra pode surgir a compreensão do conflito. Segundo Bohn, "uma só pessoa pode ter um sentimento dialógico dentro de si se o 
MONTEIRO, Valdênia Brito. Justiça restaurativa à luz dos direitos humanos: fundamentos a partir de Paulo

espírito do diálogo estiver presente. No diálogo todos vencem" (2005, p.34). A manifestação da indignação é um ato consciente de quem não aceita a injustiça, a exclusão. "Falo da resistência, da indignação da 'justa ira', dos traídos e dos enganados. Do seu direito e do seu dever de rebelar-se contra as transgressões éticas de que são vítimas cada vez mais sofridas" (Freire, 2004, p.114).

\section{O desafio da justiça restaurativa}

Todo ato de restauração é difícil, porque se faz necessário sair do lugar do medo, do confronto, do luto e da dor para viver a superação, a resiliência ${ }^{7}$, a responsabilização do conflito entre as partes envolvidas.

Observa-se que a culpa e a punição circundam constantemente nossas atitudes, por isso é tão difícil vivenciar a justiça restaurativa, porque a racionalidade humana tenta resolver a culpa transformando-a em punição, o que traz muita dor e sofrimento. "A dinâmica de punição retira o poder que as pessoas têm de transformar conflitos e aprender com eles" (Penido, 2010, p.14). Quando o assunto remete ao poder punitivo, Batista diz que "o poder se alimenta do seu próprio método: não resolve o conflito, mas põe em funcionamento o mecanismo que vai unir simbolicamente a culpa com castigo" (2012, p.31).

Na realidade, nunca saímos totalmente da barbárie, o que nos leva a um comportamento de vingança, que significa a violência retroalimentada pelo circuito da violência. A justiça retributiva tem como base a culpa. A justiça restaurativa é diferente do sistema tradicional de justiça criminal e dispõe que: 1. A questão do crime é uma violação nas relações entre as pessoas, ao causar um mal à vítima, à comunidade e ao próprio autor do delito; 2. Que todos devem se envolver num processo de restauração de um trauma, quer individual quer social. Freire (2004) apresenta a importância da autonomia, da consciência, do saber dialogar. E o mais importante: "Assumir-se como ser social e histórico, como ser pensante, comunicante, transformador, criador, realizador de sonhos, capaz de ter raiva porque capaz de amar" (Freire, 2004, p.46).

A justiça restaurativa se mostra como uma oportunidade concreta que os envolvidos expressem os seus sentimentos, exponham como foram afetados pelo acontecimento e possam promover práticas de pacificação interpessoal e comunitária. A justiça constrói um diálogo com

\footnotetext{
${ }^{7}$ Resiliência significa a capacidade de enfrentar as adversidades da vida e se recompor após uma situação aflitiva enfrentada.

DIGNIDADE RE-VISTA | ISSN2525-698X| 2021 | V. VII | N. 12 | Educação Prática Libertadora - heranças dos 100 anos de Paulo Freire e Dom Paulo Arns. Pastoral Universitária Anchieta PUC-RIO.
} 
o intuito do aprendizado da responsabilização, das obrigações, das necessidades de todos os envolvidos. Como expressa Freire,

O respeito à autonomia e à dignidade de cada um é um imperativo ético e não um favor que podemos ou não conceder uns aos outros. Precisamente porque éticos podemos desrespeitar a rigorosidade da ética e resvalar para a sua negação, por isso é imprescindível deixar claro que a possibilidade do desvio ético não pode receber outra designação senão a de transgressão. (2004, p.6667)

\section{Considerações finais}

O debate sobre a aplicação da justiça restaurativa à luz dos direitos humanos, como instrumento da cultura de paz e possibilidade de uma política pública preventiva, é incipiente e em construção. Apesar dos debates no Brasil, não resta dúvida que a justiça restaurativa se trata de um novo foco que pode ser aplicado para resolução de conflitos em vários âmbitos. As contribuições deixadas por Freire (2004) fornecem elementos para construir ações de práticas libertadoras e da inclusão do outro, a partir de um projeto de sociedade coletivo, consciente de que outro mundo é possível. A cultura da punição, do medo, da culpa, da subserviência, neutraliza a capacidade de estabelecer diálogo e a cultura de paz. A justiça restaurativa é um modelo que busca que o cidadão seja capaz de assumir de forma crítica a responsabilidade, ao mesmo tempo que envolve todos na solução do conflito. É um caminho para a construção de uma cultura de direitos humanos.

Neste momento do centenário de vida e obra de Paulo Freire, é importante reforçar a concepção teórico-prática do intelectual, que tinha um projeto societário de cultura de paz e de direitos humanos com o objetivo de dar sentido à humanidade, consciente do homem como ser em constante mudança, mas capaz de solidariedade, cooperação, construção coletiva e novos aprendizados. Reafirmando Freire, o diálogo é necessidade existencial. 


\section{Referências bibliográficas}

BOHN, David. Diálogo: comunicação e redes de convivência. Trad. Humberto Mariotti. São Paulo: Palas Athenas, 2005.

DUSSEL. Enrique. Filosofia da libertação: crítica à ideologia da exclusão. Trad. Georges Maissiat. SãoPaulo: Paulus, 1995.

FREIRE. Ana Maria. Educação para a paz segundo Paulo Freire. Educação, PUC/RS, Porto Alegre, ano XXXiX, n.2, mai/ago 2006.

FREIRE. Ana Maria. Algumas reflexões em torno da utopia. In: FREIRE, Ana Maria de Araújo (org.). Pedagogia dos sonhos possíveis. São Paulo: Unesp, 2001 b.

FREIRE, Paulo. Pedagogia da autonomia. 29.ed. São Paulo: Paz e Terra, 2004.

FREIRE, Paulo. Pedagogia do oprimido. São Paulo: Paz e Terra, 2005.

FREIRE, Paulo. Educação e mudança. 30.ed. São Paulo: Paz e Terra, 2007.

FREIRE, Paulo. Pedagogia da autonomia. Saberes necessários à prática educativa. 1996. Disponível em: < http://www.letras.ufmg.br/espanhol/pdf/pedagogia_da_autonomia__paulofreire.pdf>. Acesso em: 8 abr 2021.

GALTUNG. Johan. O caminho é a meta: Gandhi hoje. Trad. Humberto Mariotti. São Paulo: Palas Athenas, 2003.

LEDERACH, John Paul. Construyendo la paz: Reconciliacion sostenible en sociedades dívidas. Gernika, Vizcaya: Gernika Gogoratuz/Centro de Investigación por la Paz, 1998.

MBEMBE, Achille. Necropolítica: biopoder, soberania, estado de exceção, política da morte. Trad. Renata Santini. São Paulo: n-1 edições, 2018.

MULLER, J. M. O princípio da não violência: uma trajetória filosófica. São Paulo: Palas Athena, 2007.2 Disponível em: <http://www.gajop.org.br/arquivos/publicacoes/justica_cidada.pdf>. Acesso em: 4 mai 2021.

ONU. Declaração e programa de ação sobre uma cultura de paz. Disponível em: <http://www.comitepaz.org.br/download/Declara\%C3\%A7\%C3\%A3o\%20e\%20Programa\%2 0de\%20A\%C3\%A7\%C3\%A3o\%20sobre\%20uma\%20Cultura\%20de\%20Paz\%20$\% 20$ ONU.pdf> Acesso em: 30 mar 2021.

NORBERTO, Bobbio. A era do direito. São Paulo. LTC, 1992.

PENIDO, Egberto de Almeida. A arte do encontro na justiça. Casa em revista, ano II, n.3, 2010. 
MONTEIRO, Valdênia Brito. Justiça restaurativa à luz dos direitos humanos: fundamentos a partir de Paulo

PELIZZOLI, Marcelo. Reflexões a partir dos fundamentos e do método da comunicação não violenta (CNV). Mediação de conflitos, direitos humanos e acesso à justiça.

QUIJANO, Aníbal. Colonialidade do poder e classificação social. In: SANTOS, B. de Sousa (org). Epistemologias do Sul. São Paulo: Cortez, 2013.

SANTOS, Boaventura Sousa. (org). Epistemologias do Sul. São Paulo: Cortez, 2013.

RUIZ, Carlos M. M. Bartolomé. Justiça e memória: para uma crítica ética da violência. São Leopoldo: Editora Unisinos, 2009.

ZEHR, Howard. Trocando as lentes - um novo foco sobre o crime e a justiça. São Paulo: Palas Athena, 2008. 